\title{
DESIGN AND DEVELOPMENT OF A POTATO SLICING MACHINE
}

\author{
Osama M. Abd El-Haq*, El-Sayed G. Khater**, \\ Adel H. Bahnasawy*** and Hossam M.T. El-Ghobashy****
}

ABSTRACT

The main aim of the present study is to design, fabricate and evaluate a slicing machine for potato chips to be used in small and medium production units locally available materials like stainless steel and mild steel were used in fabrication. The obtained results indicated that the machine productivity increased from 256.021 to 387.670, 201.879 to 448.670 and 250.070 to $392.290 \mathrm{~kg} \mathrm{~h}^{-1}$ with increasing potato size from small to large, slice thickness from 1.0 to $2.5 \mathrm{~mm}$ and slice thickness from 1.0 to $2.5 \mathrm{~mm}$, respectively. The uniformity index increased from 76.598 to $83.372,73.472$ to 87.103 and 73.615 to $86.422 \%$ with increasing potato size from small to large, slice thickness from 1.0 to $2.5 \mathrm{~mm}$ and slicer thickness from 1.0 to $2.5 \mathrm{~mm}$, respectively. The cutting efficiency increased from 87.582 to 93.305 and 89.531 to $92.209 \%$ with increasing potato size from small to large, slice thickness from 1.0 to $2.5 \mathrm{~mm}$, respectively, while it decreased from 92.325 to $89.829 \%$ with increasing cutting speed from 250 to $550 \mathrm{rpm}$, respectively. The specific energy consumption decreased from 2.446 to $1.663,3.042$ to 1.464 and 2.608 to $1.578 \mathrm{~W} . \mathrm{h} \mathrm{kg}^{-1}$ with increasing potato size from small to large, slice thickness from 1.0 to $2.5 \mathrm{~mm}$ and cutting speed from 250 to $550 \mathrm{rpm}$, respectively. The total cost of slicing machine decreased from 0.085 to $0.055,0.102$ to 0.044 and 0.091 to $0.054 \mathrm{LE} \mathrm{kg}^{-1}$ with increasing potato size from small to large, slice thickness from 1.0 to $2.5 \mathrm{~mm}$ and cutting speed from 250 to 550 rpm, respectively.

Keywords: Slicing Machine, Potato, Productivity, Uniformity Index, Efficiency

\footnotetext{
* Graduate Student of Agric. Eng. Dep., Fac. of Agric., Benha Univ., Egypt ** Lecturer. of Agric. Eng., Fac. of Agric., Benha Univ., Egypt *** Professor. of Agric. Eng., Fac. of Agric., Benha Univ., Egypt **** Researcher, Agric. Eng. Res. Inst., Agric. Res. Center, Egypt
} 


\section{INTRODUCTION}

$\mathrm{P}$ otato is one of the most important vegetable crops grown in all countries. In Egypt, potato is a major export crop. The total cultivated area of potato is about 325000 feddan (135416.7 ha). This area produced about 2.8 million Mg in 2014 according to CAPMS (2014). Most of this potato is consumed as chips.

The chips and other snack foods in the world accounts for overall turnover of 2.2 billion dollars considering 70 manufacturing and technology research centers in the world. Also the quality of chips plays a vital role in the hotel management. Due to uneven thickness of the slices arising from improper tools, a lot of wastage of vegetables is happening leading to loss of productivity and other miscellaneous damages to vegetables. The chips makers are at the risk of injuring their fingers and having difficulty in producing the type of slices they wanted (Kartika and Arahanth, 2014).

The slicing technology has already been developed mature abroad in 1970s, in the mid-eighties most of the slicers can process monocrystal with large diameter up to $125 \mathrm{~mm}$ (5 inches), like the horizontal inside diameter slicing machine manufactured by Mayer Bbu Geyer company in Switzerland which can slice materials with the maximum diameter up to p304.8 $\mathrm{mm}$ (12 inches). In the following one or two years in the mideighties, the slicing technology has experienced its peak of development, many of the automatic multi-function slicers have been commercialized (Xie, 1996).

The reduction in size of agricultural products is brought about by mechanical means without change in chemical properties of the materials. They are used to improve the eating quality or suitability of foods for further processing and to increase the range of available products. With the development of a variety of cutting tools for size reduction, a lot of drudgery had been removed from processes which hitherto were tedious to accomplish. The size of agricultural products may be reduced several ways. The main methods used are crushing, impact, shearing and cutting. Size reducing devices include crushers, slicers, grinders, and hammer mills (Fellow, 2003). 
Cutting has been described as the continuous process in which penetration of a sharp knife through a material result in a new surface due to failure in shear accompanied by deformation in bending and compression (Lawson, 2004). The method is particularly well adapted to the reduction of sizes of vegetables, fruits, fish, meat, roots and tubers. Cutting operation for large scale processing is used severally today in food processing industries, outdoor catering services, confectionaries, snacks centers and restaurants.

The slicer consists of material inlet system, cutting system, material outlet system and manual elevator system. The material inlet system is very simple; because it's a household slicer which doesn't have a large quantity to slice, the manual feed is used. It not only lowers the costs, but also reduces the size of the slicer (He et al., 2013).

The design of the slicer is in accordance with principles of ergonomics, easy to operate, convenient, safe and high stability. The shape and appearance, which is simple and decent, occupy less space and easy to carry, has greater aesthetic value. The overall structure is concise and reasonable (Jiang, 2013).

Several types of cutting machine are available. These include knives with one cutting edge, shear with two cutting edges and saw with many cutting edges. They may be operated manually or electrically (Wilson and Kirk, 1982).

After careful study of indigenous way of potato slicing, it was observed that it involves a lot of physical labor and material wastage. Therefore, to improve the processing method and enhance it hygienic level, there is need of mechanization of the slicing method. The main aim of the present study is to design, fabricate and evaluate a slicing machine for potato chips to be used in small and medium production units, such as restaurants and hotels in order to save time and energy.

\section{MATERIALS AND METHODS}

The main experiment was carried out at Agricultural and Bio-Systems Engineering Department, Faculty of Agriculture Moshtohor, Benha University, Egypt, during the period of 2015 season to design, fabricate and evaluate a slicing machine for potato chips. 


\subsection{Machine description:}

The electrically operated potato slicing machine was designed, fabricated and evaluated. Figures (1 and 2) show the isometric drawing and the orthographic drawing of the machine. The components of the machine include the machine frame, the feeding unit, cutting unit and power transmission unit.

\subsubsection{The machine frame:}

The main frame of the machine was constructed from steel angles $(30 \times 30 \times 3 \mathrm{~mm}$ for wide, high and thickness, respectively). Dimensions of the machine frame are $650 \mathrm{~mm}$ long, $450 \mathrm{~mm}$ for wide and $850 \mathrm{~mm}$ for high. All important parts of slicing machine were constructed from antirust materials.

\subsubsection{Feeding unit:}

The potatoes are fed manually, one by one into the hopper that attached with the pusher plate and has lever. The lever (handle) can be raised and lowered by hinge to feed and push the potatoes by pusher plate into the slicing zone (rotating plate). The handle can be adjusted to prevent the pusher plate from coming in contact with the plate or blade.

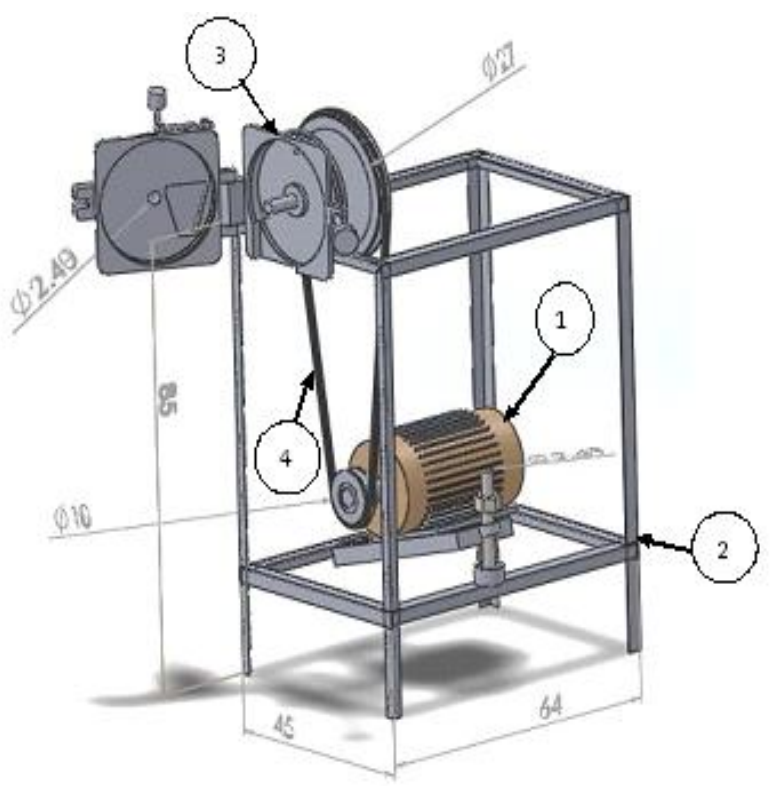

Figure (1): Isometric drawing of the slicing machine.
1. Motor
2. Frame
3. Cutting Unit
4. Belt 

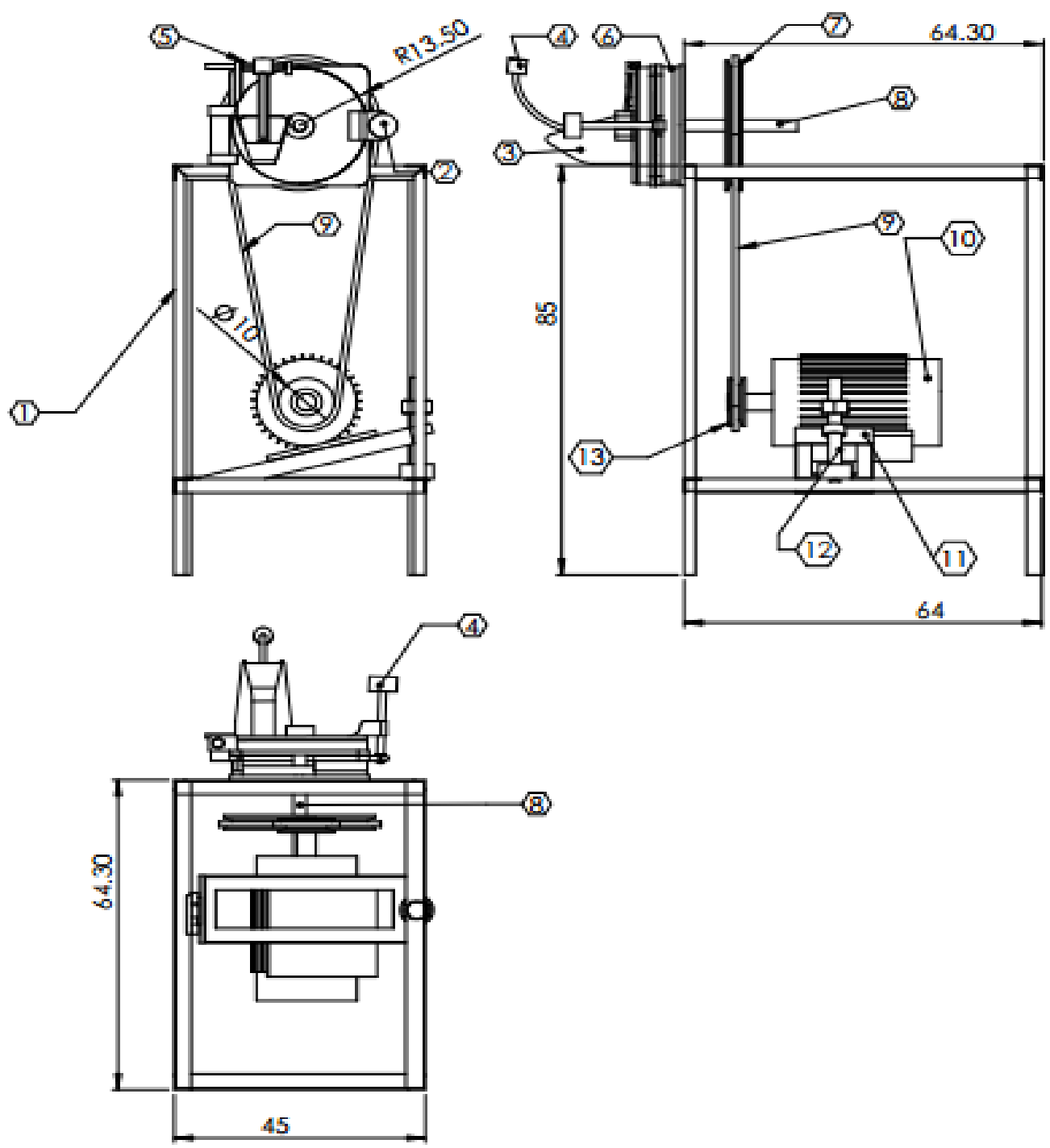

Figure (2): Orthographic drawing of the slicing machine.

1. Main frame

2. Locking pin

3. Feeding door

4. Feeding Handle

5. Handle hinge

\section{Housing}

7. Cutting shaft pulley

8. Cutting shaft

9. V- shape belt

10. Electric motor
11. Motor base

12. V- belt adjustment screw

13. Motor pulley

The hopper opening built-with the slicer door that can be opened to change the various types of rotating plates. To close the door after plate changing, the locking pin was used. 


\subsubsection{Cutting unit:}

The cutting unit consists of two main parts:

The first part is cutting blades: Three stainless steel cutting blades are installed on the circular plate ( $230 \mathrm{~mm}$ diameter and made of copper); the blades can be raised and lowered by bolts (adjustable slicer blades). To adjust the thickness of the slices the spacers between the blades and the circular plate were designed. To obtain the thicker or thinner slices, just increase or decrease the spaces behind the blades to the desired width by loosening the bolts, and then fix the bolt. The available range of slicer thickness plate is between 1 to $20 \mathrm{~mm}$.

The second part is the housing: The housing is used to hold and release the various plates inside the cavity of it. In the center of the housing, the hole of the shaft which transfers the motion from motor to the rotating plate was constructed. To remove slice plate assembly from housing, the door was opened and raised the locking pin and the assembly will be free for removal by pulling outward. The cut potatoes (slices) are discharged through the lower end of the housing. The body of slicer which comprises of the door and housing were formed from raw molten aluminum.

\subsubsection{Transmission system:}

The machine cutting is driven by $0.75 \mathrm{~kW}(1.0 \mathrm{hp})$, single phase electric motor. The power was transmitted to main shaft of the slicer by different changeable sizes of pulleys and V-shaped belts, to regulate the speed of motor from $1488 \mathrm{rpm}$ to the required cutting speeds, which are 250, 350, 450 and $550 \mathrm{rpm}\left(3,4.2,5.4\right.$ and $\left.6.6 \mathrm{~m} \mathrm{~s}^{-1}\right)$.

\subsection{Treatment:}

The treatments were arranged in a randomized complete block design in five replications. Three potato sizes are small size $<50 \mathrm{~mm}$, medium size from 50 to $80 \mathrm{~mm}$ and large size $>80 \mathrm{~mm}$. Four cutting speeds are 250 , 350,450 and $550 \mathrm{rpm}$. Four slice thicknesses are 1, 1.5, 2 and $2.5 \mathrm{~mm}$.

\subsection{Measurements}

\subsubsection{Machine productivity:}

The machine productivity $\left(\mathrm{kg} \mathrm{h}^{-1}\right)$ was defined as the load of the potato divided by the total cutting time. The machine productivity was estimated from equation: 


$$
\operatorname{Pr}=\frac{L}{T}
$$

Where:

Pr is the machine productivity, $\mathrm{kg} \mathrm{h}^{-1}$

$\mathrm{L}$ is the load, $\mathrm{kg}$

$\mathrm{T}$ is the load time, $\mathrm{h}$

\subsubsection{Slice size uniformity index:}

The uniformity of size of slice was determined by sorting out the different size ranges of cut. The uniformity Index (U.I) was computed from the relationship below according to (Akande et al., 2008).

$$
U . I=\frac{\text { No. of } \text { chips with same dimension }}{\text { Total No. of chips collected }} \times 100
$$

Where:

U.I is the uniformity index, \%

\subsubsection{Loss percentage:}

Loss percentage incurred by machine was estimated from equation:

$$
P . L=\frac{\text { Total mass of sample }- \text { Massafter cutting }}{\text { Total mass }} \times 100
$$

Where:

P.L is the percentage of loss, \%

\subsubsection{Machine cutting efficiency:}

Machine cutting efficiency was estimated from equation:

$$
\eta=(100-P . L)
$$

Where:

$\eta$ is the machine slicing efficiency, \%

\subsubsection{Power and energy requirement for slicing machine:}

The power requirement $(\mathrm{kW})$ was estimated by using the clamp meter to measure the line current strength (I) and the potential difference value (V).

The total electric power requirement under machine working load (P) was calculated according to Kurt (1979) by the following equation:

$$
P=\frac{I \times V \times \cos \theta}{1000}
$$

Where:

$\mathrm{P}$ is the power requirement to cutting potato, $\mathrm{kW}$ 
PROCESS ENGINEERING

I is the line current strength, Amperes.

$\mathrm{V}$ is the potential difference, Voltage.

$\operatorname{Cos} \theta$ is the power factor, equal 0.8 .

The specific energy consumption (SEC) in $\mathrm{kW} \cdot \mathrm{h} \mathrm{kg}^{-1}$ was calculated by using the following equation:

$$
S E C=\frac{P}{\operatorname{Pr}}
$$

Where:

SEC is the specific energy consumption, W. $\mathrm{h} \mathrm{kg}^{-1}$

\subsection{Total Costs:}

Hourly cost is calculated according to the equation that is given by Awady (1978) as follows:

$$
C=\frac{p}{h}\left(\frac{1}{a}+\frac{i}{2}+t+r\right)+(\mathrm{w} \times \mathrm{e})+\frac{\mathrm{m}}{\mathrm{k}}
$$

Where:

$\mathrm{C}$ is the hourly cost, $\mathrm{LE} \mathrm{h}^{-1}$

$\mathrm{p}$ is the price of the equipment, $\mathrm{LE}$

$\mathrm{h}$ is the year by working hours, $\mathrm{h}$

$\mathrm{a}$ is the life expected of the machine, year

$\mathrm{i}$ is the Interest rate, \%

$\mathrm{t}$ is the taxes and over heads ratio, \%

$\mathrm{r}$ is the repair and maintenance ratio, $\%$

$\mathrm{w}$ is the power of motor in, $\mathrm{kW}$

$\mathrm{e}$ is the electricity cost, $\mathrm{LE} \mathrm{kW}^{-1} \mathrm{~h}^{-1}$

$\mathrm{m}$ is the operator monthly salary, LE.

$\mathrm{k}$ is the monthly average working hours.

Cost inputs are listed in table (1).

Table (1): Cost inputs.

\begin{tabular}{|l|c|}
\hline \multicolumn{1}{|c|}{ Items } & Cost, LE \\
\hline Price of equipment, LE. & 3000 \\
\hline Motor, $\mathrm{kW}$ & 1.0 \\
\hline Expected life, year & 5 \\
\hline Taxes, \% & 3 \\
\hline Repair, \% & 10 \\
\hline Interest, \% & 10 \\
\hline Labors, $\mathrm{LE} \mathrm{h}^{-1}$ & 10 \\
\hline
\end{tabular}




\subsection{Statistical analysis}

The statistical analysis for the data obtained was done according to Snedecor and Cochran (1980) and the treatments were compared using Least Significant Differences (LSD) test at 99\% confidence level (Gomez, 1984).

\section{RESULTS AND DISCUSSIONS}

\subsection{Machine productivity:}

Table (2) and Figures (3, 4 and 5) show the machine productivity of the potato slicing as affected by the potato size from small $(>50 \mathrm{~mm})$ to large ( $<80 \mathrm{~mm}$ ), the slice thickness from 1.0 to $2.5 \mathrm{~mm}$ and cutting speed from 250 to $550 \mathrm{rpm}$. The results indicate that the machine productivity increases with increasing potato size, slice thickness and cutting speed.

Table (2): Machine productivity at different potato sizes, slice thicknesses and cutting speeds.

\begin{tabular}{|c|c|c|c|c|c|c|c|c|}
\hline \multirow[t]{3}{*}{ Size, $\mathrm{mm}$} & \multirow{3}{*}{$\begin{array}{c}\text { Thickness, } \\
\mathrm{mm}\end{array}$} & \multicolumn{6}{|c|}{ Cutting speed, rpm } & \multirow[t]{3}{*}{ Mean } \\
\hline & & 250 & 350 & 450 & & & 550 & \\
\hline & & \multicolumn{6}{|c|}{ Machine Productivity, $\mathrm{kg} \mathrm{h}^{-1}$} & \\
\hline \multirow{5}{*}{ Small } & 1.0 & 102.742 & 164.646 & \multicolumn{2}{|c|}{189.746} & \multicolumn{2}{|c|}{203.342} & $185.911^{\mathrm{a}}$ \\
\hline & 1.5 & 157.224 & 187.910 & \multicolumn{2}{|c|}{218.900} & \multicolumn{2}{|c|}{230.332} & $212.381^{\mathrm{a}}$ \\
\hline & 2.0 & 196.802 & 268.900 & \multicolumn{2}{|c|}{323.362} & \multicolumn{2}{|c|}{352.602} & $314.955^{\mathrm{c}}$ \\
\hline & 2.5 & 268.802 & 339.363 & \multicolumn{2}{|c|}{409.494} & \multicolumn{2}{|c|}{482.170} & $410.342^{c d}$ \\
\hline & Mean & 207.6093 & 265.391 & \multicolumn{2}{|c|}{317.252} & \multicolumn{2}{|c|}{ 355.0347 } & \\
\hline \multirow{5}{*}{ Medium } & 1.0 & 132.122 & 192.058 & \multicolumn{2}{|c|}{229.636} & & $202.417^{\mathrm{a}}$ \\
\hline & 1.5 & 219.774 & 233.342 & \multicolumn{2}{|c|}{246.778} & \multicolumn{2}{|c|}{$\begin{array}{l}255.850 \\
306.928\end{array}$} & $251.706^{b}$ \\
\hline & 2.0 & 287.100 & 352.222 & \multicolumn{2}{|c|}{427.928} & \multicolumn{2}{|c|}{472.594} & $384.961^{d}$ \\
\hline & 2.5 & 366.404 & 426.468 & \multicolumn{2}{|c|}{481.984} & \multicolumn{2}{|c|}{542.968} & $454.456^{\mathrm{e}}$ \\
\hline & Mean & 251.35 & 301.0225 & \multicolumn{2}{|c|}{346.5815} & \multicolumn{2}{|c|}{394.585} & \\
\hline \multirow{5}{*}{ Large } & 1.0 & 140.936 & 221.326 & \multicolumn{2}{|c|}{262.552} & \multicolumn{2}{|c|}{327.590} & $238.101^{\mathrm{ab}}$ \\
\hline & 1.5 & 323.382 & 335.794 & \multicolumn{2}{|c|}{348.594} & \multicolumn{2}{|c|}{409.458} & $354.307^{d}$ \\
\hline & 2.0 & 360.192 & 393.140 & 483.4 & & \multicolumn{2}{|c|}{532.732} & $442.376^{\mathrm{e}}$ \\
\hline & 2.5 & 445.360 & 504.194 & 525.9 & & & 0.914 & $516.595^{\mathrm{f}}$ \\
\hline & Mean & 317.4675 & 363.6135 & 405.1 & & & 1735 & \\
\hline Mean of size (A) & 256 & $21^{\mathrm{a}}$ & 323 & $385^{\mathrm{b}}$ & & & 387. & $845^{\mathrm{c}}$ \\
\hline Mean of thickness (B) & 201.8 & & $268.201^{\mathrm{b}}$ & & 0.9 & & & $448.670^{\mathrm{d}}$ \\
\hline Mean of Speed (C) & 250.0 & & $301.614^{\mathrm{b}}$ & & $\overline{5.6}$ & & & $392.290^{\mathrm{d}}$ \\
\hline LSD at 0.05 & A & $\mathrm{B}$ & $\mathrm{C}$ & $\mathrm{AB}$ & & $\mathrm{C}$ & $\mathrm{BC}$ & $\mathrm{ABC}$ \\
\hline & 23.372 & 26.988 & 26.988 & 46.749 & & $S$ & 53.932 & N.S \\
\hline
\end{tabular}




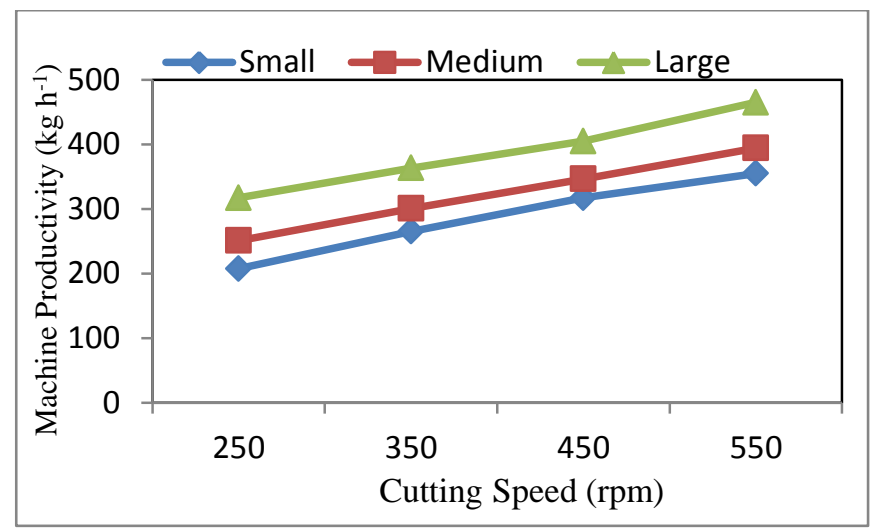

Figure (3): Machine productivity at different potato sizes and cutting speeds.

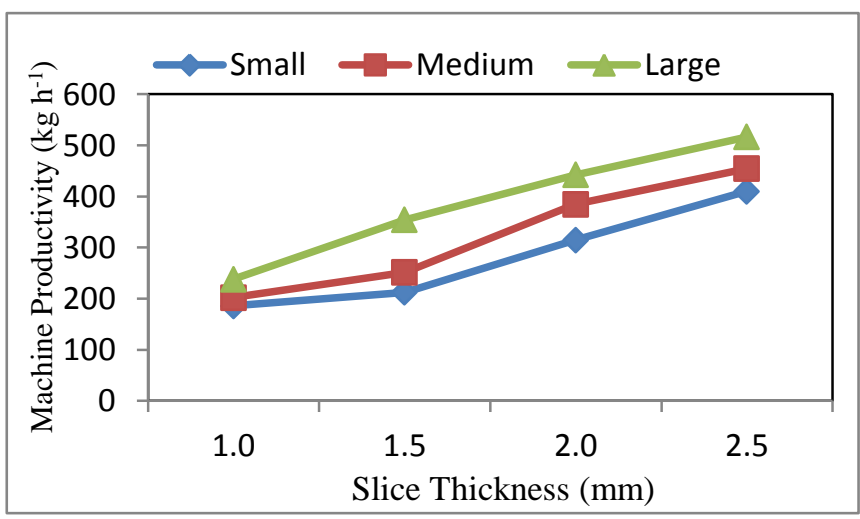

Figure (4): Machine productivity at different potato sizes and slice thicknesses.

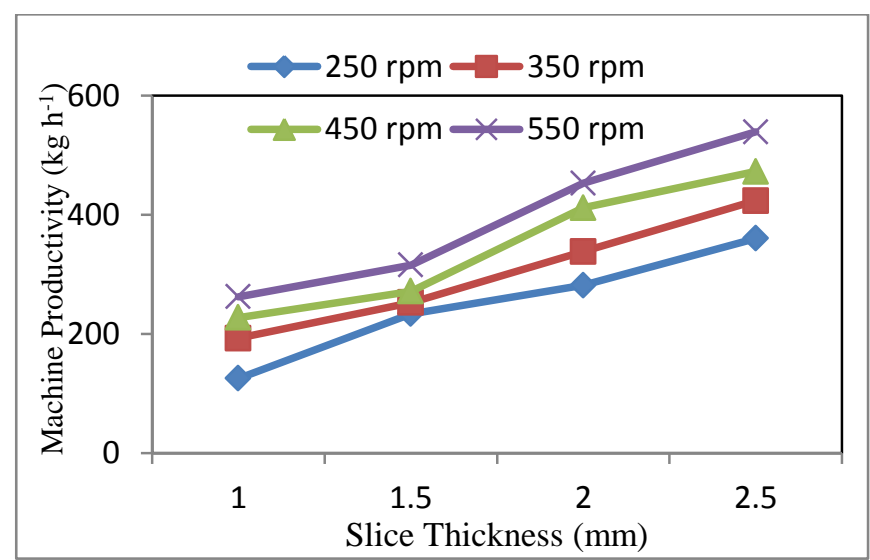

Figure (5): Machine productivity at different slice thicknesses and cutting speeds. 
It indicates that when the potato size increased from small to large, the machine productivity significantly increased from 256.021 to 387.670 (by $33.96 \%) \mathrm{kg} \mathrm{h}^{-1}$. It also indicates that when the slice thickness increased from 1.0 to $2.5 \mathrm{~mm}$, the machine productivity significantly increased from 201.879 to 448.670 (by $55.01 \%$ ) $\mathrm{kg} \mathrm{h}^{-1}$, while the machine productivity significantly increased from 250.070 to 392.290 (by $36.25 \%$ ) $\mathrm{kg} \mathrm{h}^{-1}$ when the cutting speed increased from 250 to $550 \mathrm{rpm}$.

It could be noticed that increasing the potato size from small $(<50 \mathrm{~mm})$ to large $(>80 \mathrm{~mm})$, tends to increase the machine productivity from 207.61 to $317.47,265.39$ to $363.61,317.25$ to 405.12 and 355.03 to $465.17 \mathrm{~kg} \mathrm{~h}^{-1}$ at $250,350,450$ and $550 \mathrm{rpm}$ cutting speeds, respectively. The results also indicate that the machine productivity increased from 207.61 to $355.03,251.35$ to 394.59 and 317.47 to $465.17 \mathrm{~kg} \mathrm{~h}^{-1}$ at small ( $\left.<50 \mathrm{~mm}\right)$, medium $(50-80 \mathrm{~mm})$ and large $(>80 \mathrm{~mm})$ potato sizes, respectively when the cutting speed increased from 250 to $550 \mathrm{rpm}$ as shown in figure (3). The trend of these results agreed with those obtained by Aniyi (2006) and Fayose (2007).

Regarding the effect of potato size and slice thickness on the machine productivity, the results indicate that the machine productivity increases with increasing the potato size and slice thickness. It increased from 185.91 to $238.10,212.38$ to $354.31,314.96$ to 442.38 and 410.34 to $516.60 \mathrm{~kg} \mathrm{~h}^{-1}$ at 1.0, 1.5, 2.0 and $2.5 \mathrm{~mm}$ slice thickness, respectively, when the potato size increased from small $(<50 \mathrm{~mm})$ to large $(>80 \mathrm{~mm})$. The results also indicate that the machine productivity increased from 185.91 to $410.34,202.42$ to 454.46 and 238.10 to $516.60 \mathrm{~kg} \mathrm{~h}^{-1}$ at small $(<50 \mathrm{~mm})$, medium $(50-80 \mathrm{~mm})$ and large $(>80 \mathrm{~mm})$, respectively, when the slice thickness increased from 1.0 to $2.5 \mathrm{~mm}$ as shown in figure (4).

The results also indicate that the machine productivity increased from 125.27 to $360.19,192.68$ to $423.34,227.31$ to 472.46 and 262.26 to $538.68 \mathrm{~kg} \mathrm{~h}^{-1}$ at 250, 350, 450 and $550 \mathrm{rpm}$ cutting speed, respectively, when the slice thickness increased from 1.0 to $2.5 \mathrm{~mm}$. The results also indicate that the machine productivity increased from 125.27 to 262.26 , 233.46 to $315.57,281.37$ to 452.64 and 360.19 to $538.68 \mathrm{~kg} \mathrm{~h}^{-1}$ at 1.0 , $1.5,2.0$ and $2.5 \mathrm{~mm}$ slice thickness, respectively, when the cutting speed increased from 250 to $550 \mathrm{rpm}$ as shown in figure (5). 
Multiple regression analysis was carried out to obtain a relationship between the machine productivity as dependent variable and different both of slice thickness and cutting speed as independent variables. The best fit for this relationship is presented in the following equation:-

$$
M P=-160.96+168.62 S T+0.47 C S \quad \mathrm{R}^{2}=0.97
$$

Where:

MP is the machine productivity, $\mathrm{kg} \mathrm{h}^{-1}$

ST is the slicer thickness, $\mathrm{mm}$

CS is the cutting speed, rpm

This equation is applied in the range of 1.0 to $2.5 \mathrm{~mm}$ slice thickness and from 250 to $550 \mathrm{rpm}$ of cutting speed.

\subsection{Uniformity index:}

Table (3) and Figures (6, 7 and 8) show the uniformity index of the potato slicing as affected by the potato size from small $(>50 \mathrm{~mm})$ to large $(<80$ $\mathrm{mm}$ ), the slice thickness from 1.0 to $2.5 \mathrm{~mm}$ and cutting speed from 250 to $550 \mathrm{rpm}$. The results indicate that the machine productivity increases with increasing potato size, slice thickness and cutting speed. It indicates that when the potato size increased from small to large, the uniformity index significantly increased from 76.598 to 83.372 (by $8.13 \%$ ) \%. It also indicates that when the slice thickness increased from 1.0 to $2.5 \mathrm{~mm}$, the uniformity index significantly increased from 73.472 to 87.103 (by $15.65 \%) \%$, while the uniformity index significantly increased from 73.615 to 86.422 (by $14.82 \%$ ) \% when the cutting speed increased from 250 to $550 \mathrm{rpm}$.

Figure (6) shows the effect of potato size and cutting speed on the uniformity index. It is obvious that the uniformity index increased with increasing cutting speed from 250 to $550 \mathrm{rpm}$ at different potato sizes. It could be seen that the uniformity index values were 72.331, 74.409, 76.792 and $82.862 \%$, respectively, at small potato size, while they were from $72.180,82.127,85.184$ and $88.311 \%$, respectively, at medium potato size and $76.332,82.854,86.201$ and $88.894 \%$, respectively, at large potato size, when the cutting speeds were $250,350,450$ and 550 rpm. 
Table (3): Uniformity index at different potato sizes, slice thicknesses and cutting speeds.

\begin{tabular}{|c|c|c|c|c|c|c|c|}
\hline \multirow[t]{3}{*}{ Size, mm } & \multirow{3}{*}{$\begin{array}{c}\text { Thicknes } \\
\text { s, }\end{array}$} & \multicolumn{5}{|c|}{ Cutting speed, rpm } & \multirow[t]{3}{*}{ Mean } \\
\hline & & 250 & 350 & 450 & & & \\
\hline & & \multicolumn{5}{|c|}{ Uniformity index, $\%$} & \\
\hline \multirow{5}{*}{ Small } & 1.0 & 63.554 & 62.200 & 68.46 & \multicolumn{2}{|c|}{73.954} & $67.043^{a}$ \\
\hline & 1.5 & 66.822 & 68.326 & $70.5 \mathrm{C}$ & \multicolumn{2}{|c|}{81.246} & $71.7465^{\mathrm{a}}$ \\
\hline & 2.0 & 74.952 & 81.960 & 82.68 & \multicolumn{2}{|c|}{87.216} & $81.702^{b}$ \\
\hline & 2.5 & 83.998 & 85.150 & 85.42 & \multicolumn{2}{|c|}{89.032} & $85.902^{\mathrm{c}}$ \\
\hline & Mean & $72.331^{\mathrm{a}}$ & $74.409^{\mathrm{a}}$ & 76.79 & \multicolumn{2}{|c|}{$82.862^{b}$} & \\
\hline \multirow{5}{*}{ Medium } & 1.0 & 61.118 & 76.182 & 82.16 & \multicolumn{2}{|c|}{83.684} & $75.788^{a b}$ \\
\hline & 1.5 & 71.120 & 80.972 & 84.35 & \multicolumn{2}{|c|}{87.138} & $80.905^{b}$ \\
\hline & 2.0 & 74.612 & 84.910 & 85.98 & \multicolumn{2}{|c|}{89.950} & $83.865^{\text {bc }}$ \\
\hline & 2.5 & 81.870 & 86.442 & $88.1 \mathrm{C}$ & \multicolumn{2}{|c|}{92.470} & $87.244^{\mathrm{c}}$ \\
\hline & Mean & $72.18^{a}$ & $82.127^{b}$ & 85.18 & \multicolumn{2}{|c|}{$\mathbf{8 8 . 3 1 1}^{b}$} & \\
\hline \multirow{5}{*}{ Large } & 1.0 & 65.974 & 76.120 & 82.72 & & & $77.586^{b}$ \\
\hline & 1.5 & 75.848 & 79.080 & 86.44 & & & $82.033^{b}$ \\
\hline & 2.0 & 79.872 & 86.268 & 86.98 & & & $85.705^{\mathrm{c}}$ \\
\hline & 2.5 & 83.634 & 89.946 & 88.67 & & & $88.164^{c}$ \\
\hline & Mean & $76.332^{\mathrm{a}}$ & $82.854^{b}$ & 86.20 & & $94^{b}$ & \\
\hline Mean of size (A) & \multicolumn{2}{|c|}{$76.598^{\mathrm{a}}$} & \multicolumn{2}{|c|}{$81.950^{\mathrm{a}}$} & \multicolumn{3}{|c|}{$83.372^{\mathrm{b}}$} \\
\hline Mean of thickness(B) & \multicolumn{2}{|c|}{$73.472^{\mathrm{a}}$} & $78.228^{b}$ & \multicolumn{3}{|c|}{$83.757^{\mathrm{c}}$} & $87.103^{c}$ \\
\hline Mean of Speed (C) & \multicolumn{2}{|c|}{$73.615^{\mathrm{a}}$} & $79.796^{\mathrm{b}}$ & \multicolumn{3}{|c|}{$82.728^{\mathrm{b}}$} & $86.422^{\mathrm{bc}}$ \\
\hline \multirow[t]{2}{*}{ LSD at 0.05} & A & $\mathrm{B}$ & $\mathrm{C}$ & $\mathrm{AB}$ & $\mathrm{AC}$ & $\mathrm{BC}$ & $\mathrm{ABC}$ \\
\hline & 3.247 & 3.749 & 3.749 & 6.494 & 9.494 & 7.4 & N.S \\
\hline
\end{tabular}




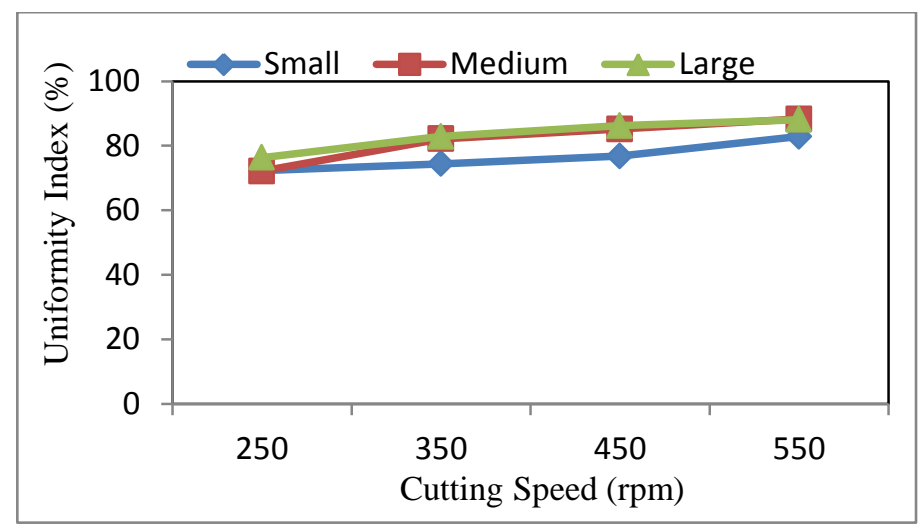

Figure (6): Uniformity index at different potato sizes and cutting speeds.

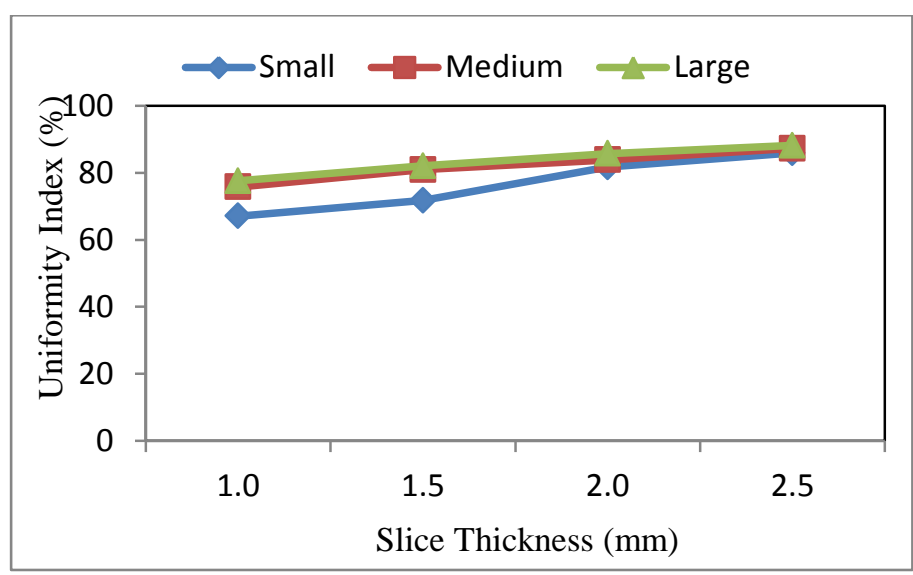

Figure (7): Uniformity index at different potato sizes and slice thicknesses.

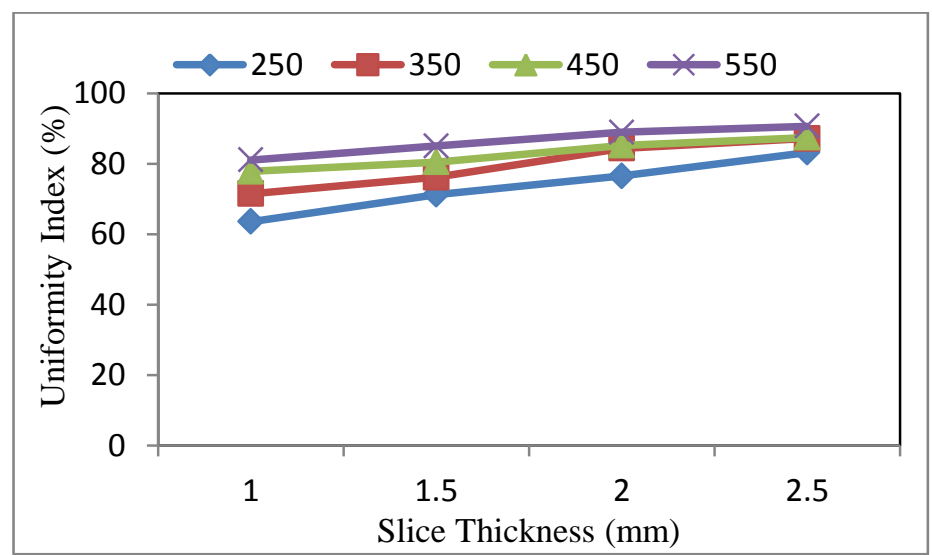

Figure (8): Uniformity index at different slice thicknesses and cutting speeds. 
Figure (7) shows the effect of potato size and slice thickness on the uniformity index. It is clear that the uniformity index increased with increasing slice thickness from 1.0 to $2.5 \mathrm{~mm}$ at different potato sizes. The results indicated that the uniformity index ranged from 67.043, $71.747,81.702$ and $85.902 \%$, respectively, at small potato size, while it ranged from $75.788,80.905,83.865$ and $87.244 \%$, respectively, at medium potato size and it ranged from 77.586, 82.033, 85.705 and 88.164 $\%$, respectively, at large potato size, when the slice thicknesses were 1.0, $1.5,2.0$ and $2.5 \mathrm{~mm}$.

Figure (8) shows the effect of cutting speed and slice thickness on the uniformity index. The results indicate that the uniformity index increases with increasing the cutting speed and slicer thickness. It increased from 63.549 to $81.054,71.263$ to $85.047,76.479$ to 88.953 and 83.167 to $90.635 \%$ at $250,350,450$ and $550 \mathrm{rpm}$ cutting speed, respectively, when the slice thickness increased from 1.0 to $2.5 \mathrm{~mm}$. The results also indicate that the uniformity index increased from 63.549 to $83.167,71.007$ to $87.179,77.786$ to 87.432 and 84.054 to $90.635 \%$ at $1.0,1.5,2.0$ and 2.5 $\mathrm{mm}$ slice thickness, respectively, when the cutting speed increased from 250 to $550 \mathrm{rpm}$.

Multiple regression analysis was carried out to obtain a relationship between the uniformity index as dependent variable and different both of slice thickness and cutting speed as independent variables. The best fit for this relationship is presented in the following equation:-

$$
U I=47.85+9.29 S T+0.041 C S \quad \mathrm{R}^{2}=0.93
$$

Where:

UI is the uniformity index, $\%$

This equation is applied in the range of 1.0 to $2.5 \mathrm{~mm}$ slice thickness and from 250 to 550 rpm cutting speed.

\subsection{Slicing efficiency:}

Table (4) and Figures (9, 10 and 11) show the slicing efficiency as affected by the potato size from small $(>50 \mathrm{~mm})$ to large $(<80 \mathrm{~mm})$, the slice thickness from 1.0 to $2.5 \mathrm{~mm}$ and cutting speed from 250 to 550 rpm. The results indicate that the slicing efficiency increases with increasing potato size and slice thickness and it decreases with increasing cutting speed. It indicates that when the potato size increased from small 
to large, the cutting efficiency significantly increased from 87.582 to 93.305 (by $6.13 \%$ ) \%. It also indicates that when the slice thickness increased from 1.0 to $2.5 \mathrm{~mm}$, the slicing efficiency significantly increased from 89.531 to 92.209 (by $2.90 \%$ ) \%. On the other hand, the slicing efficiency significantly decreased from 92.325 to 89.829 (by $2.70 \%) \%$ when the cutting speed increased from 250 to $550 \mathrm{rpm}$.

Table (4): Slicing efficiency at different potato sizes, slice thicknesses and cutting speeds.

\begin{tabular}{|c|c|c|c|c|c|c|c|c|}
\hline \multirow[t]{3}{*}{ Size, mm } & \multirow{3}{*}{$\begin{array}{c}\text { Thickness, } \\
\text { mm }\end{array}$} & \multicolumn{6}{|c|}{ Cutting speed, rpm } & \multirow[t]{3}{*}{ Mean } \\
\hline & & 250 & 350 & & & & 550 & \\
\hline & & \multicolumn{6}{|c|}{ Slicing Efficiency, \% } & \\
\hline \multirow{5}{*}{ Small } & 1.0 & 85.882 & 85.650 & \multicolumn{2}{|c|}{84.673} & \multicolumn{2}{|c|}{84.510} & 85.179 \\
\hline & 1.5 & 88.861 & 88.465 & \multicolumn{2}{|c|}{87.157} & \multicolumn{2}{|c|}{86.763} & 87.812 \\
\hline & 2.0 & 89.474 & 88.755 & \multicolumn{2}{|c|}{87.321} & \multicolumn{2}{|c|}{86.92} & 88.112 \\
\hline & 2.5 & 90.779 & 89.936 & \multicolumn{2}{|c|}{88.562} & \multicolumn{2}{|c|}{87.597} & 89.219 \\
\hline & Mean & 88.749 & 88.202 & \multicolumn{2}{|c|}{86.928} & \multicolumn{2}{|c|}{86.448} & \\
\hline \multirow{5}{*}{ Medium } & 1.0 & 92.916 & 91.883 & \multicolumn{2}{|c|}{90.713} & \multicolumn{2}{|c|}{90.595} & 91.527 \\
\hline & 1.5 & 93.264 & 93.011 & \multicolumn{2}{|c|}{91.452} & \multicolumn{2}{|c|}{90.834} & 92.140 \\
\hline & 2.0 & 93.721 & 93.648 & \multicolumn{2}{|c|}{92.399} & \multicolumn{2}{|c|}{91.469} & 92.809 \\
\hline & 2.5 & 94.218 & 93.956 & \multicolumn{2}{|c|}{92.795} & \multicolumn{2}{|c|}{91.965} & 93.234 \\
\hline & Mean & 93.529 & 93.125 & \multicolumn{2}{|c|}{91.839} & \multicolumn{2}{|c|}{91.216} & \\
\hline \multirow{5}{*}{ Large } & 1.0 & 92.482 & 92.095 & \multicolumn{2}{|c|}{91.584} & \multicolumn{2}{|c|}{91.394} & 91.889 \\
\hline & 1.5 & 95.044 & 94.254 & \multicolumn{2}{|c|}{93.918} & \multicolumn{2}{|c|}{90.925} & 93.535 \\
\hline & 2.0 & 95.316 & 93.82 & \multicolumn{2}{|c|}{93.251} & & .088 & 93.619 \\
\hline & 2.5 & 95.981 & 94.203 & 93. & & & .887 & 94.176 \\
\hline & Mean & 94.706 & 93.593 & 93. & & & .824 & \\
\hline Mean of size (A) & 87.5 & & & $427^{\mathrm{b}}$ & & & 93. & $05^{\mathrm{b}}$ \\
\hline Mean of thickness(B) & 89.531 & & $91.162^{\mathrm{b}}$ & & U & & & $2.209^{\mathrm{b}}$ \\
\hline Mean of Speed (C) & 92.328 & & $91.639^{\mathrm{ab}}$ & & .6 & & & $39.829^{\mathrm{a}}$ \\
\hline LSD at 0.05 & A & B & $\mathrm{C}$ & $\mathrm{AB}$ & & & $\mathrm{BC}$ & $\mathrm{ABC}$ \\
\hline & 2.251 & 1.629 & 1.629 & N.S & & & N.S & N.S \\
\hline
\end{tabular}




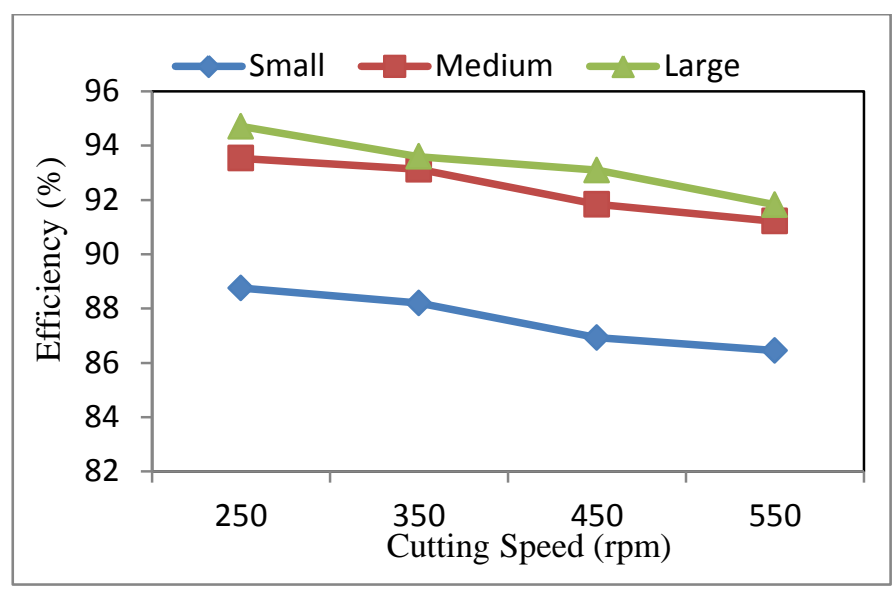

Figure (9): Slicing efficiency at different potato sizes and cutting speeds.

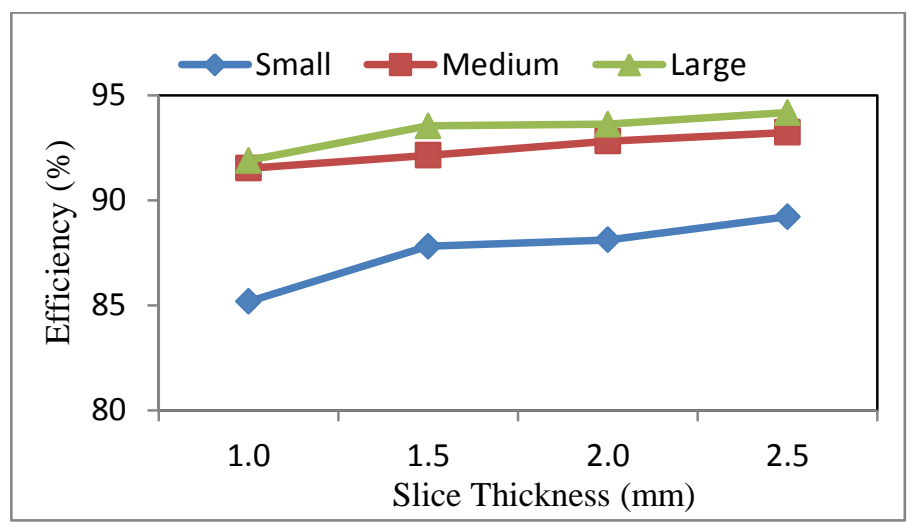

Figure (10): Slicing efficiency at different potato sizes and slicer thicknesses.

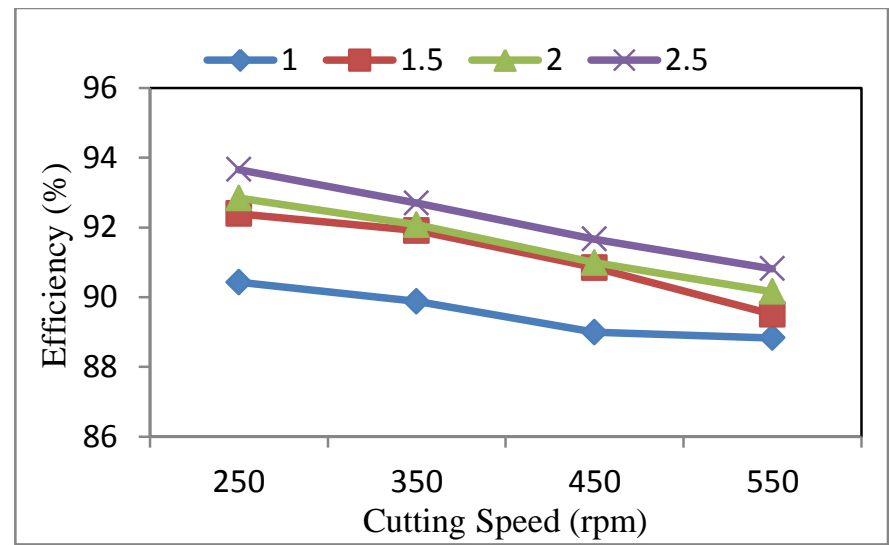

Figure (11): Slicing efficiency at different slice thicknesses and cutting speeds. 
Figure (9) shows the effect of potato size and cutting speed on the slicing efficiency. The results indicate that the slicing efficiency decreased with increasing cutting speed from 250 to $550 \mathrm{rpm}$ at different potato sizes. It could be seen that when the cutting speed increased from 250 to $550 \mathrm{rpm}$ slicing efficiency decreased from 88.749 to $86.448,93.529$ to 91.216 and 94.706 to $91.824 \%$, respectively, at small, medium and large potato size, while it increased from 88.749 to $94.706,88.202$ to $93.593,86.928$ to 93.097 and 86.448 to $91.824 \%$, respectively, at 250, 350, 450 and 550 rpm cutting speed, when the potato size increased small $(<50 \mathrm{~mm})$ to large $(>80 \mathrm{~mm})$.

Figure (10) shows the effect of potato size and slice thickness on the slicing efficiency. It is clear that the cutting efficiency increased with increasing slicer thickness from 1.0 to $2.5 \mathrm{~mm}$ at different potato sizes. The results indicated that the slicing efficiency ranged from 85.179, $87.812,88.118$ and $89.219 \%$, respectively, at small potato size, while it ranged from 91.527, 92.140, 92.809 and $93.234 \%$, respectively, at medium potato size and it ranged from 91.889, 93.535, 93.619 and 94.176 $\%$, respectively, at large potato size, when the slice thicknesses were 1.0, $1.5,2.0$ and $2.5 \mathrm{~mm}$.

Figure (11) shows the effect of cutting speed and slice thickness on the slicing efficiency. The results indicate that the slicing efficiency increased from 90.427 to $93.659,89.876$ to $92.698,88.990$ to 91.663 and 88.833 to $90.816 \%$ at $250,350,450$ and $550 \mathrm{rpm}$ cutting speed, respectively, when the slice thickness increased from 1.0 to $2.5 \mathrm{~mm}$. The results also indicate that the slicing efficiency decreased from 90.427 to $88.833,92.389$ to 89.507, 92.837 to 90.159 and 93.659 to $90.816 \%$ at 1.0, 1.5, 2.0 and 2.5 $\mathrm{mm}$ slice thickness, respectively, when the cutting speed increased from 250 to $550 \mathrm{rpm}$.

Multiple regression analysis was carried out to obtain a relationship between the slicing efficiency as dependent variable and different both of slice thickness and cutting speed as independent variables. The best fit for this relationship is presented in the following equation:-

$$
C F=91.576+1.677 S T-0.008 C S \quad \mathrm{R}^{2}=0.92
$$

Where: 
$\mathrm{CF}$ is the slicing efficiency, \%

This equation is applied in the range of 1.0 to $2.5 \mathrm{~mm}$ slice thickness and from 250 to $550 \mathrm{rpm}$ cutting speed.

\subsection{Specific energy consumption:}

Table (5) and Figures (12, 13 and 14) show the specific energy consumption of the potato slicing as affected by the potato size from small $(>50 \mathrm{~mm})$ to large $(<80 \mathrm{~mm})$, the slice thickness from 1.0 to 2.5 $\mathrm{mm}$ and cutting speed from 250 to $550 \mathrm{rpm}$.

Table (5): Specific energy consumption at different potato sizes, slice thicknesses and cutting speeds.

\begin{tabular}{|c|c|c|c|c|c|c|c|}
\hline \multirow[t]{3}{*}{ Size, $\mathrm{mm}$} & \multirow{3}{*}{$\begin{array}{c}\text { Thickness, } \\
\text { mm }\end{array}$} & \multicolumn{5}{|c|}{ Cutting speed, rpm } & \multirow{2}{*}{ Mean } \\
\hline & & 250 & 350 & 450 & & 50 & \\
\hline & & \multicolumn{5}{|c|}{ Specific Energy Consumption, W.h kg-1 } & \\
\hline \multirow{5}{*}{ Small } & 1.0 & 6.003 & 3.716 & 3.182 & & 889 & $3.948^{\mathrm{e}}$ \\
\hline & 1.5 & 4.027 & 3.355 & 2.869 & & 570 & $3.205^{\mathrm{d}}$ \\
\hline & 2.0 & 3.317 & 2.367 & 1.966 & & 735 & $2.346^{c}$ \\
\hline & 2.5 & 2.489 & 1.901 & 1.572 & & 286 & $1.812^{\mathrm{b}}$ \\
\hline & Mean & 3.959 & 2.835 & 2.397 & & 120 & \\
\hline \multirow{5}{*}{ Medium } & 1.0 & 4.697 & 3.213 & 2.674 & & 385 & $3.242^{\mathrm{d}}$ \\
\hline & 1.5 & 2.922 & 2.738 & 2.553 & & 020 & $2.558^{\mathrm{c}}$ \\
\hline & 2.0 & 2.302 & 1.855 & 1.493 & & 333 & $1.746^{\mathrm{ab}}$ \\
\hline & 2.5 & 1.861 & 1.554 & 1.337 & & 170 & $1.480^{\mathrm{a}}$ \\
\hline & Mean & 2.945 & 2.340 & 2.014 & & 727 & \\
\hline \multirow{5}{*}{ Large } & 1.0 & 4.482 & 2.823 & 2.359 & & 865 & $2.882^{\mathrm{cd}}$ \\
\hline & 1.5 & 2.031 & 1.909 & 1.807 & & 525 & $1.818^{b}$ \\
\hline & 2.0 & 1.861 & 1.676 & 1.328 & & 187 & $1.513^{\mathrm{a}}$ \\
\hline & 2.5 & 1.548 & 1.338 & 1.259 & & 107 & $1.313^{\mathrm{a}}$ \\
\hline & Mean & 2.480 & 1.937 & 1.688 & & 421 & \\
\hline Mean of size (A) & \multicolumn{2}{|c|}{$2.446^{\mathrm{c}}$} & \multicolumn{2}{|c|}{$1.971^{\mathrm{b}}$} & \multicolumn{3}{|c|}{$1.663^{\mathrm{a}}$} \\
\hline Mean of thickness(B) & \multicolumn{2}{|c|}{$3.042^{\mathrm{c}}$} & $2.351^{\mathrm{b}}$ & \multicolumn{3}{|c|}{$1.735^{\mathrm{a}}$} & $1.464^{\mathrm{a}}$ \\
\hline Mean of Speed (C) & \multicolumn{2}{|c|}{$2.608^{\mathrm{d}}$} & $2.126^{\mathrm{bc}}$ & \multicolumn{3}{|c|}{$1.830^{\mathrm{a}}$} & $1.578^{\mathrm{a}}$ \\
\hline \multirow[t]{2}{*}{ LSD at 0.05} & A & B & $\mathrm{C}$ & $\mathrm{AB}$ & $\mathrm{AC}$ & $\mathrm{BC}$ & $\mathrm{ABC}$ \\
\hline & 0.201 & 0.359 & 0.359 & 46.749 & N.S & 0.5 & N.S \\
\hline
\end{tabular}




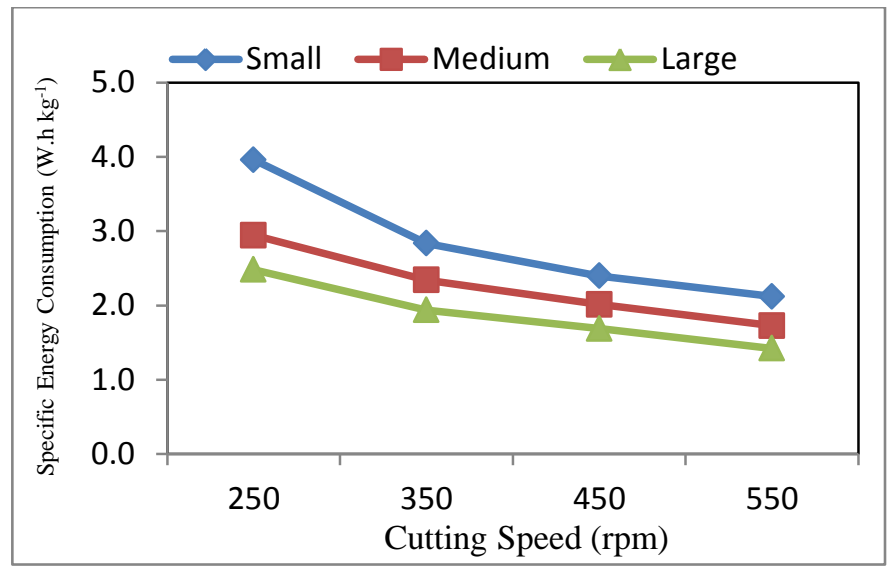

Figure (12): Specific energy consumption at different potato sizes and cutting speeds.

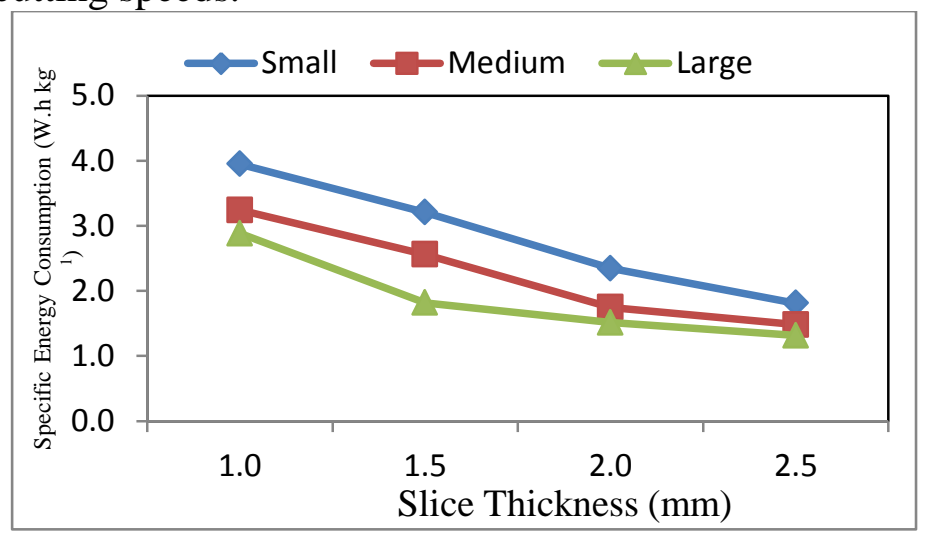

Figure (13): Specific energy consumption at different potato sizes and slice thicknesses.

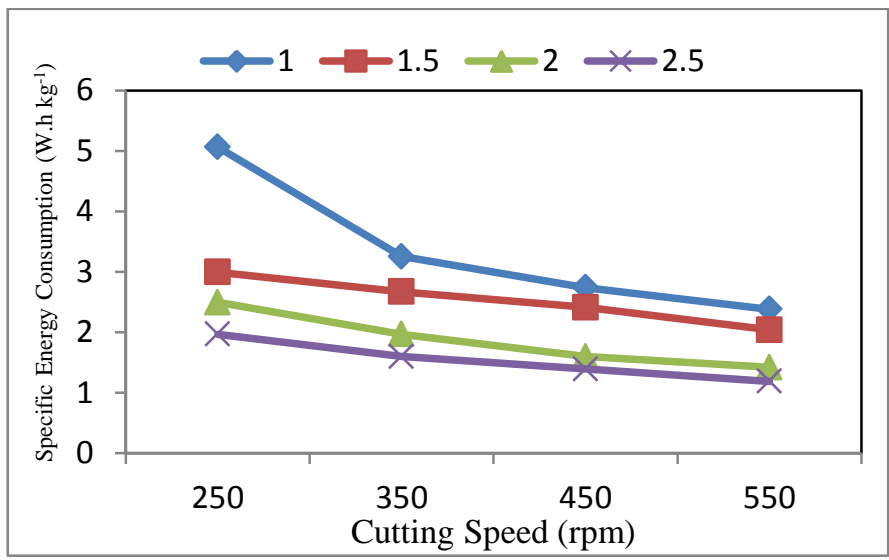

Figure (14): Specific energy consumption at different slice thicknesses and cutting speeds. 
The results indicate that the specific energy consumption decreases with increasing potato size, slice thickness and cutting speed. It indicates that when the potato size increased from small to large, the specific energy consumption significantly decreased from 2.446 to 1.663 (by 32.01\%) W.h kg ${ }^{-1}$. It also indicates that when the slice thickness increased from 1.0 to $2.5 \mathrm{~mm}$, the specific energy consumption significantly decreased from 3.042 to 1.464 (by $51.87 \%$ ) W.h kg-1 . The specific energy consumption significantly decreased from 2.608 to 1.578 (by $39.49 \%$ ) W.h kg-1, when the cutting speed increased from 250 to $550 \mathrm{rpm}$, respectively.

Figure (12) shows the effect of potato size and cutting speed on the specific energy consumption. The results indicate that the specific energy consumption decreased with increasing cutting speed from 250 to 550 rpm at different potato sizes. It could be seen that when the cutting speed increased from 250 to $550 \mathrm{rpm}$ the specific energy consumption decreased from 3.959 to $2.120,2.955$ to 1.727 and 2.480 to $1.421 \mathrm{~W} . \mathrm{h} \mathrm{kg}^{-}$ ${ }^{1}$, respectively, at small, medium and large potato size, while it decreased from 3.959 to $2.480,2.834$ to $1.947,2.397$ to 1.688 and 2.120 to 1.421 W.h kg ${ }^{-1}$, respectively, at 250, 350, 450 and $550 \mathrm{rpm}$ cutting speed, when the potato size increased small $(<50 \mathrm{~mm})$ to large $(>80 \mathrm{~mm})$.

Figure (13) shows the effect of potato size and slice thickness on the specific energy consumption. It is clear that the specific energy consumption decreased with increasing slice thickness from 1.0 to 2.5 $\mathrm{mm}$ at different potato sizes. The results indicated that the specific energy consumption ranged from 3.958, 3.215, 2.356 and $1.812 \mathrm{~W} . \mathrm{h} \mathrm{kg}^{-1}$, respectively, at small potato size, while it ranged from 3.242, 2.568, 1.746 and $1.480 \mathrm{~W} . \mathrm{h} \mathrm{kg}^{-1}$, respectively, at medium potato size and it ranged from $2.882,1.828,1.513$ and $1.313 \mathrm{~W} . \mathrm{h} \mathrm{kg}^{-1}$, respectively, at large potato size, when the slice thicknesses were 1.0, 1.5, 2.0 and $2.5 \mathrm{~mm}$.

Figure (14) shows the effect of cutting speed and slice thickness on the specific energy consumption. The results indicate that the specific energy consumption decreases with increasing the slice thickness and the cutting speed. It decreased from 5.061 to $1.967,3.251$ to $1.597,2.738$ to 1.389 and 2.379 to $1.187 \mathrm{~W} . \mathrm{h} \mathrm{kg}^{-1}$ at $250,350,450$ and $550 \mathrm{rpm}$ cutting speed, respectively, when the slice thickness increased from 1.0 to $2.5 \mathrm{~mm}$. The results also indicate that the specific energy consumption decreased from 
5.061 to $2.379,2.993$ to $2.038,2.493$ to 1.418 and 1.967 to $1.187 \mathrm{~W} . \mathrm{h} \mathrm{kg}^{-}$

${ }^{1}$ at $1.0,1.5,2.0$ and $2.5 \mathrm{~mm}$ slicer thickness, respectively, when the cutting speed increased from 250 to $550 \mathrm{rpm}$.

Multiple regression analysis was carried out to obtain a relationship between the specific energy consumption as dependent variable and different both of slice thickness and cutting speed as independent variables. The best fit for this relationship is presented in the following equation:-

$$
S E C=6.248-0.004 S T-1.225 C S \quad \mathrm{R}^{2}=0.86
$$

Where:

SEC is the specific energy consumption, W. $\mathrm{h} \mathrm{kg}^{-1}$

This equation is applied in the range of 1.0 to $2.5 \mathrm{~mm}$ slice thickness and from 250 to 550 rpm cutting speed.

\subsection{The total costs of slicing machine:}

Table (6) and Figures (15, 16 and 17) show the total costs of slicing machine of the potato slicing as affected by the potato size from small (>50 mm) to large $(<80 \mathrm{~mm})$, the slice thickness from 1.0 to $2.5 \mathrm{~mm}$ and cutting speed from 250 to $550 \mathrm{rpm}$. The results indicate that the total costs of slicing machine decreases with increasing potato size, slice thickness and cutting speed. It indicates that when the potato size increased from small to large, the total costs of slicing machine significantly decreased from 0.085 to 0.055 (by $35.29 \%$ ) $\mathrm{LE} \mathrm{kg}^{-1}$. It also indicates that when the slice thickness increased from 1.0 to $2.5 \mathrm{~mm}$, the total costs of slicing machine significantly decreased from 0.102 to 0.044 (by $56.86 \%$ ) $\mathrm{LE} \mathrm{kg}^{-}$ ${ }^{1}$. The total costs of slicing machine significantly decreased from 0.091 to 0.054 (by $40.66 \%$ ) $\mathrm{LE} \mathrm{kg}^{-1}$, when the cutting speed increased from 250 to $550 \mathrm{rpm}$, respectively.

Figure (15) shows the effect of potato size and cutting speed on the total costs of slicing machine. The results indicate that the total costs of slicing machine decreased with increasing cutting speed from 250 to $550 \mathrm{rpm}$ at different potato sizes. It could be seen that when the cutting speed increased from 250 to $550 \mathrm{rpm}$ the total costs of slicing machine decreased from 0.117 to $0.066,0.086$ to 0.052 and 0.071 to $0.042 \mathrm{LE} \mathrm{kg}^{-1}$, respectively, at small, medium and large potato size, while it decreased from 0.117 to $0.071,0.085$ to $0.056,0.72$ to 0.049 and 0.066 to $0.042 \mathrm{LE}$ 
$\mathrm{kg}^{-1}$, respectively, at $250,350,450$ and $550 \mathrm{rpm}$ cutting speed, when the potato size increased small $(<50 \mathrm{~mm})$ to large $(>80 \mathrm{~mm})$.

Figure (16) shows the effect of potato size and slice thickness on the total costs of slicing machine. It is clear that the total costs of slicing machine decreased with increasing slice thickness from 1.0 to $2.5 \mathrm{~mm}$ at different potato sizes. The results indicated that the total costs of slicing machine ranged from $0.122,0.096,0.069$ and $0.052 \mathrm{LE} \mathrm{kg}^{-1}$, respectively, at small potato size, while it ranged from $0.098,0.076,0.050$ and $0.042 \mathrm{LE} \mathrm{kg}^{-1}$, respectively, at medium potato size and it ranged from $0.086,0.053$, 0.043 and $0.037 \mathrm{LE} \mathrm{kg}^{-1}$, respectively, at large potato size, when the slicer thicknesses were 1.0, 1.5, 2.0 and $2.5 \mathrm{~mm}$.

Table (6): Total costs of slicing machine at different potato sizes, slice thicknesses and cutting speeds.

\begin{tabular}{|c|c|c|c|c|c|c|c|}
\hline \multirow[t]{3}{*}{ Size, $\mathrm{mm}$} & \multirow{3}{*}{$\begin{array}{c}\text { Thickness, } \\
\text { mm }\end{array}$} & \multicolumn{5}{|c|}{ Cutting speed, rpm } & \multirow[t]{2}{*}{ Mean } \\
\hline & & 250 & 350 & 45 & & 550 & \\
\hline & & \multicolumn{5}{|c|}{ Total Costs of Slicing Machine, $\mathrm{LE} \mathrm{kg}^{-1}$} & \\
\hline \multirow{5}{*}{ Small } & 1.0 & 0.182 & 0.114 & 0.0 & & 0.092 & $0.122^{d}$ \\
\hline & 1.5 & 0.119 & 0.100 & 0.08 & & 0.081 & $0.096^{\text {bc }}$ \\
\hline & 2.0 & 0.095 & 0.070 & 0.0 & & 0.053 & $0.069^{a b}$ \\
\hline & 2.5 & 0.070 & 0.055 & 0.0 & & 0.039 & $0.052^{\mathrm{a}}$ \\
\hline & Mean & 0.117 & 0.085 & 0.0 & & 0.066 & \\
\hline \multirow{5}{*}{ Medium } & 1.0 & 0.142 & 0.097 & 0.08 & & 0.073 & ${0.098^{c}}^{-}$ \\
\hline & 1.5 & 0.085 & 0.080 & $0.0^{\prime}$ & & 0.061 & $\mathbf{0 . 0 7 6}^{\mathrm{b}}$ \\
\hline & 2.0 & 0.065 & 0.053 & 0.0 & & 0.040 & $0.050^{\mathrm{a}}$ \\
\hline & 2.5 & 0.051 & 0.044 & 0.0 & & 0.034 & $0.042^{\mathrm{a}}$ \\
\hline & Mean & 0.086 & 0.069 & 0.0 & & 0.052 & \\
\hline \multirow{5}{*}{ Large } & 1.0 & 0.133 & 0.085 & 0.0 & & 0.057 & $0.086^{b}$ \\
\hline & 1.5 & 0.058 & 0.056 & 0.0 & & 0.046 & $0.053^{\mathrm{a}}$ \\
\hline & 2.0 & 0.052 & 0.048 & 0.0 & & 0.035 & $0.043^{\mathrm{a}}$ \\
\hline & 2.5 & 0.042 & 0.037 & 0.0 & & 0.032 & $0.037^{\mathrm{a}}$ \\
\hline & Mean & 0.071 & 0.056 & 0.0 & & 0.042 & \\
\hline Mean of size (A) & \multicolumn{2}{|c|}{$0.085^{\mathrm{c}}$} & \multicolumn{3}{|c|}{$0.067^{\mathrm{b}}$} & \multicolumn{2}{|c|}{$0.055^{\mathrm{a}}$} \\
\hline Mean of thickness (B) & \multicolumn{2}{|c|}{$0.102^{\mathrm{c}}$} & $0.075^{\mathrm{b}}$ & \multicolumn{3}{|c|}{$0.054^{\mathrm{a}}$} & $0.044^{\mathrm{a}}$ \\
\hline Mean of Speed (C) & \multicolumn{2}{|c|}{$0.091^{\mathrm{c}}$} & $0.070^{\mathrm{ab}}$ & \multicolumn{2}{|c|}{$0.061^{\mathrm{a}}$} & & $0.054^{\mathrm{a}}$ \\
\hline \multirow[t]{2}{*}{ LSD at 0.05} & A & B & $\mathrm{C}$ & $\mathrm{AB}$ & $\mathrm{AC}$ & $\mathrm{BC}$ & $\mathrm{ABC}$ \\
\hline & 0.012 & 0.014 & 0.014 & 0.20 & N.S & 0.019 & N.S \\
\hline
\end{tabular}


Figure (17) shows the effect of cutting speed and slice thickness on the total costs of slicing machine. The results indicate that the total costs of slicing machine decreases with increasing the slice thickness and the cutting speed. It decreased from 0.152 to $0.074,0.087$ to $0.062,0.071$ to 0.043 and 0.054 to $0.035 \mathrm{LE} \mathrm{kg}^{-1}$ at $250,350,450$ and $550 \mathrm{rpm}$ cutting speed, respectively, when the slicer thickness increased from 1.0 to 2.5 $\mathrm{mm}$. The results also indicate that the total costs of slicing machine decreased from 0.152 to $0.054,0.099$ to $0.045,0.084$ to 0.040 and 0.074 to $0.035 \mathrm{LE} \mathrm{kg}^{-1}$ at $1.0,1.5,2.0$ and $2.5 \mathrm{~mm}$ slice thickness, respectively, when the cutting speed increased from 250 to $550 \mathrm{rpm}$.

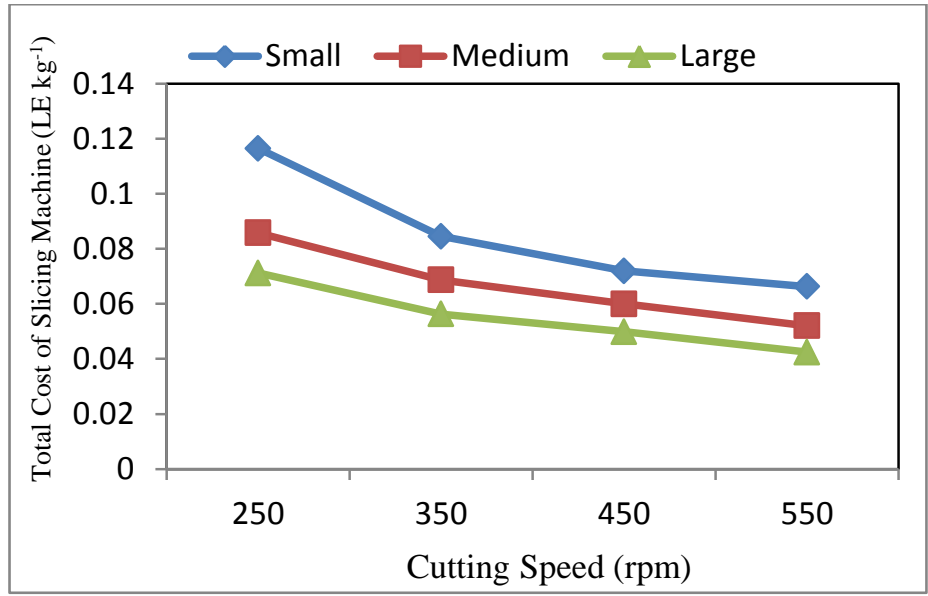

Figure (15): Total costs of slicing machine at different potato sizes and cutting speeds.

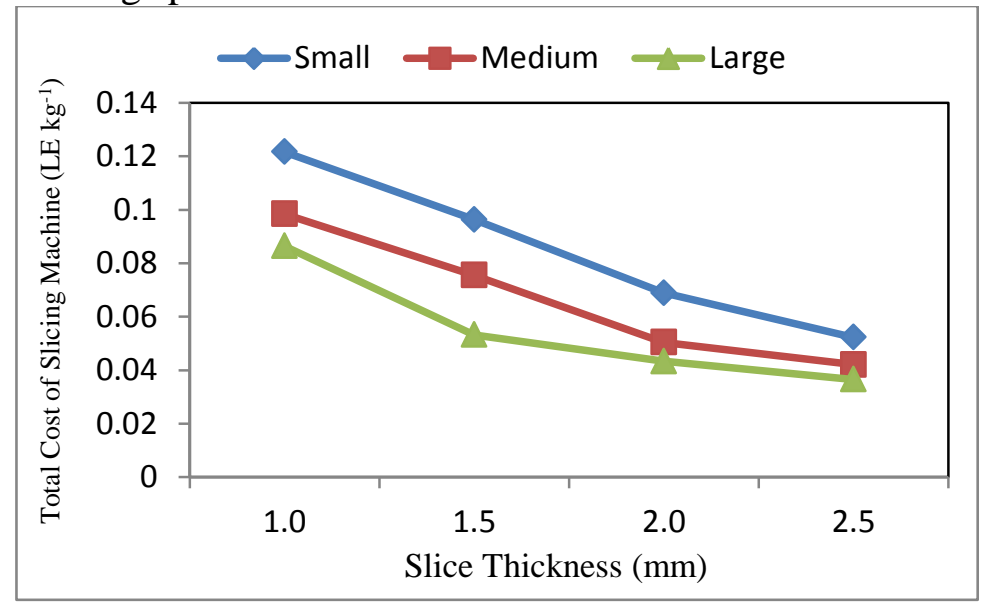

Figure (16): Total costs of slicing machine at different potato sizes and slice thicknesses. 


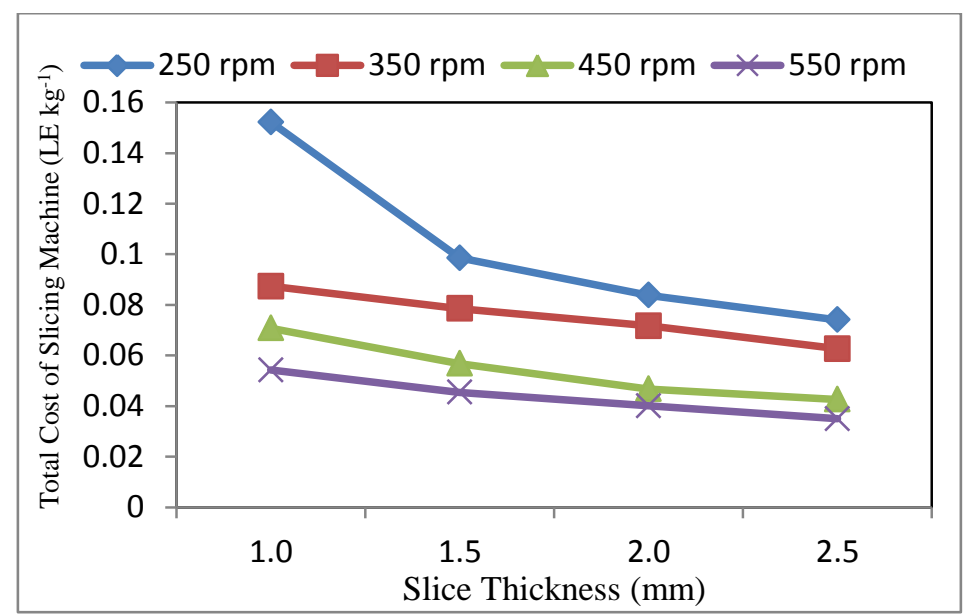

Figure (17): Total costs of slicing machine at different slice thicknesses and cutting speeds.

Multiple regression analysis was carried out to obtain a relationship between the total costs of slicing machine as dependent variable and different both of slice thickness and cutting speed as independent variables. The best fit for this relationship is presented in the following equation:-

$$
T C=0.190-0.024 S T-0.0002 C S \quad \mathrm{R}^{2}=0.82
$$

Where:

$\mathrm{TC}$ is the total costs of slicing machine, $\mathrm{LE} \mathrm{kg}^{-1}$

This equation is applied in the range of 1.0 to $2.5 \mathrm{~mm}$ slice thickness and from 250 to $550 \mathrm{rpm}$ cutting speed.

\section{CONCLUSION}

The experiment was carried out to study is to design, fabricate and evaluate a cutting machine for potato chips to be used in small and medium production units. The obtained results can be summarized as follows:

- The machine productivity increased from 256.021 to $387.670 \mathrm{~kg} \mathrm{~h}^{-1}$ with increasing potato size from small to large, respectively. It also increased from 201.879 to $448.670 \mathrm{~kg} \mathrm{~h}^{-1}$ with increasing slice thickness from 1.0 to $2.5 \mathrm{~mm}$, respectively, while it increased from 250.070 to $392.290 \mathrm{~kg} \mathrm{~h}^{-1}$ with increasing cutting speed from 250 to $550 \mathrm{rpm}$, respectively. 
- The uniformity index increased from 76.598 to $83.372 \%$ with increasing potato size from small to large, respectively. It also increased from 73.472 to $87.103 \%$ with increased slice thickness from 1.0 to $2.5 \mathrm{~mm}$, respectively, while it increased from 73.615 to $86.422 \%$ with increasing cutting speed from 250 to $550 \mathrm{rpm}$, respectively.

- The cutting efficiency increased from 87.582 to $93.305 \%$ with increasing potato size from small to large, respectively. It also increased from 89.531 to $92.209 \%$ with increasing slice thickness from 1.0 to $2.5 \mathrm{~mm}$, respectively, while it decreased from 92.325 to $89.829 \%$ with increasing cutting speed from 250 to $550 \mathrm{rpm}$, respectively.

- The specific energy consumption decreased from 2.4496 to 1.663W.h $\mathrm{kg}^{-1}$ with increasing potato size from small to large, respectively. It also decreased from 3.042 to 1.464 W.h kg ${ }^{-1}$ with increasing slice thickness from 1.0 to $2.5 \mathrm{~mm}$, respectively, while it decreased from 2.608 to 1.578 W.h kg-1 with increasing cutting speed from 250 to $550 \mathrm{rpm}$, respectively.

- The total cost of slicing machine decreased from 0.085 to 0.055 $\mathrm{LEkg}^{-1}$ with increasing potato size from small to large, respectively. It also decreased from 0.102 to $0.044 \mathrm{LEkg}^{-1}$ with increasing slice thickness from 1.0 to $2.5 \mathrm{~mm}$, respectively, while it decreased from 0.091 to $0.054 \mathrm{LEkg}^{-1}$ with increasing cutting speed from 250 to 550 rpm, respectively.

\section{REFERENCES}

Akande, F.B, Adebayo, A.O., Busari R.A., 2008. Design, Fabrication And Testing Of Manually Operated Cassava Chipping Machine, Proceedings of the $28^{\text {th }}$ Annual Conference of the Nigerian Institution of Agricultural Engineers, Yola, Nigeria.

Aniyi, S.O., 2006. Design, Construction and Evaluation of a Ginger Slicing Machine, Journal of Agricultural Engineering and Technology, 14: 12-17. 
Awady, M.N., 1978. Engineering of tractors and agricultural machinery, Text book, Fac. Agric., Ain Shams Univ., 5th ed.: 164-167.

CAPMS (2014). Annual year book for general statistics. Egypt: Central Agency for Public Mobilization and Statistics of ARE.

Fayose, F.T., 2007. Development of a cutting machine for food materials. Journal of Agricultural Engineering and Technology (JAET). 15: 58-65.

Fellow, P.J., 2003. Food Processing Technology: Principles and Practice. Woodhead Publishers Limited, England.

Gomez, K.A., 1984. Statistical Procedures for Agricultural Research, 2nd ed. John Wiely \& Sons, New York, USA 680 pp.

He, W., Li, P., Yuan, Z., Zhang, Y., Xing, D., Xiang, X, Lu, H., 2013. Effect of direct sowing rates on mid-season "rice feng-liang-youxiang-1. Adv. J. Food Sci. Technol., 5(4), 422-424.

Jiang, X., 2011. The modeling design and research of multi-function electric fan. Adv. Mater. Res., 287-290: 2852-2855.

Kartika, S.B., Arahanth, 2014. Design and development of potato slicer. IOSR Journal of Mechanical and Civil Engineering (IOSRJMCE).ISSN: 2278-1684, PP: 21-26. www.iosrjournals.org.

Kurt, G., 1979. Engineering formulas. $3^{\text {rd }}$. Ed. Mc Graw - Hill book Co.

Lawson, O.S., 2004. Crop Processing. Unpublished Lecture Note. Rufus Giwa Polytechnic, Owo, Nigeria.

Snedecor, G.W., Cochran W.G., 1980. Statistical Methods, $7^{\text {th }}$ Ed., Iowa State University Press, Ames, Iowa, USA.

Wilson, M. and W. Kirk 1982. Design and operation of catering equipment. Avi Publishing Company, West port.

Xie, Z., 1996. Review of slicer development abroad. Special. Equip. Electron. Ind., 25(3), 36-42. 


\section{الملخص العربى \\ تصميم وتطوير اله لتقطيع البطاطس}

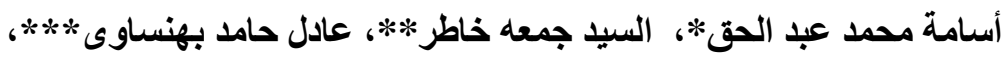

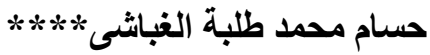

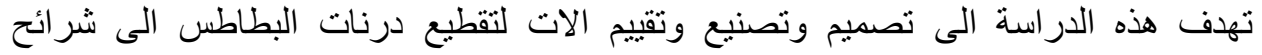

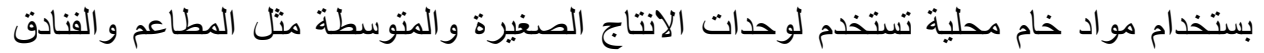
لتوفير الوقت والطاقة. وقد تم اختبار الالة تحت ظروف تاجت تشغيل مختلفة من سرعات الدورانة

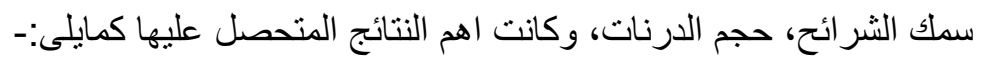
-

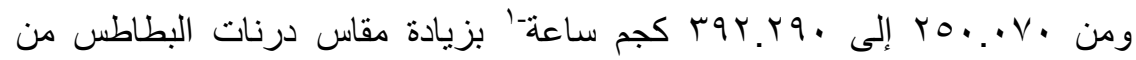

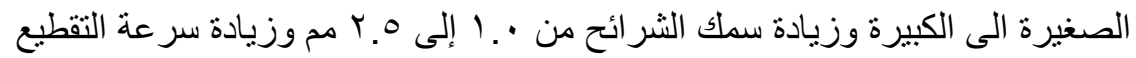

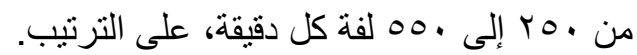

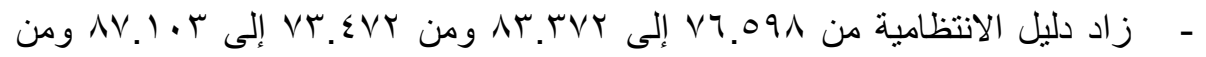

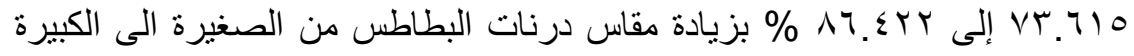

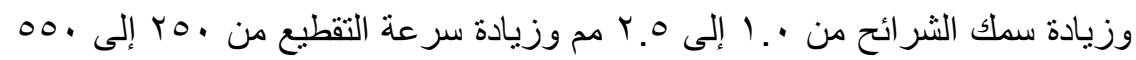
لفة كل دقيقة، على الترتيب.

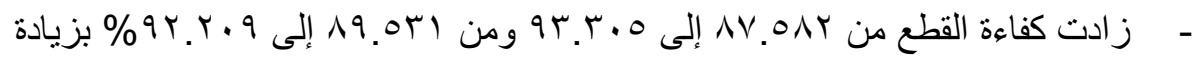

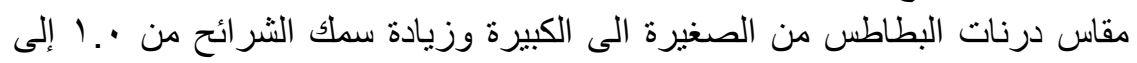

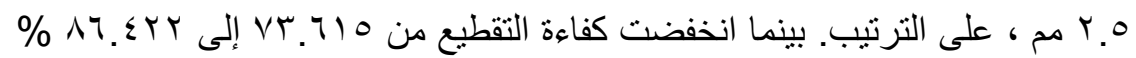

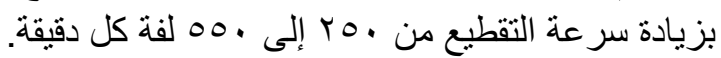

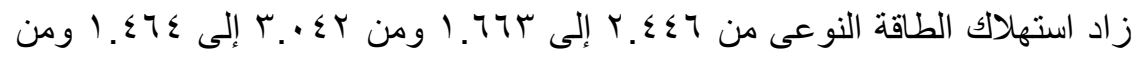

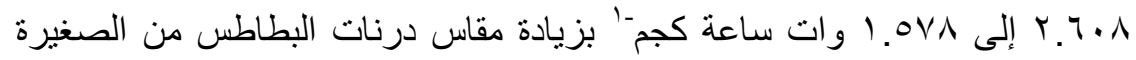

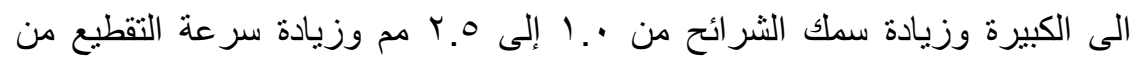

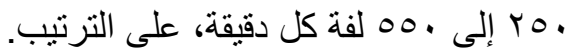

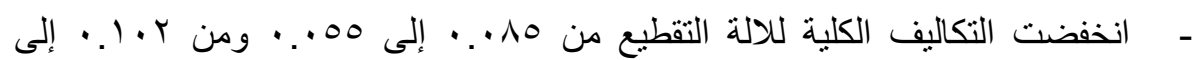

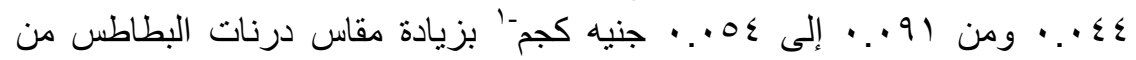

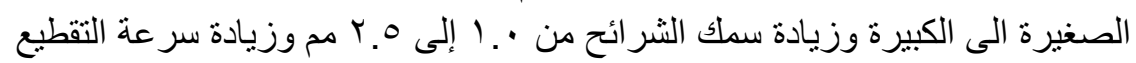

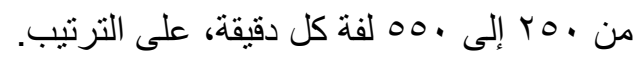

*طالب دراسات عليا - كلية الزراعة بمشتهر - جامعة بنها

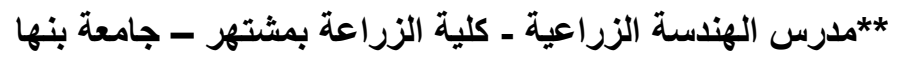

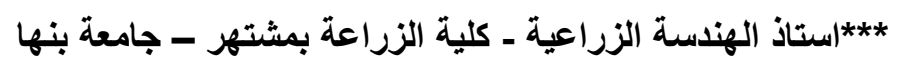

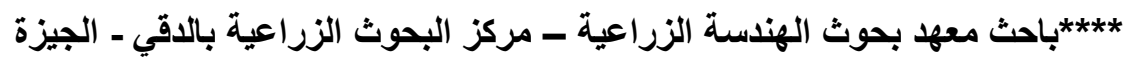

